\title{
The use of drug-eluting stents in acute myocardial infarction - is the battle coming to an end? From despair to acceptance
}

\author{
Piotr Kübler' ${ }^{1}$ Krzysztof Reczuch ${ }^{12}$ \\ ${ }^{1}$ Department of Cardiology, Military Hospital, Wroclaw, Poland \\ 2Department of Heart Diseases, Medical University, Wroclaw, Poland
}

Postep Kardiol Inter 2013; 9, 1 (31): 50-54

DOI: 10.5114/pwki.2013.34028

\begin{abstract}
The large-scale use of drug-eluting stents (DES) in elective percutaneous coronary interventions resulted in a significant reduction of restenosis and the need for repeat revascularization, compared to bare-metal stents (BMS) and balloon angioplasty. The position of DES used during primary percutaneous coronary intervention was not so well established. Based on the trials including the general population of patients, an increased risk of stent thrombosis was indicated, particularly late after implantation, which may be associated with increased mortality. A number of randomized clinical trials have compared first generation DES with BMS in acute ST-segment elevation myocardial infarction (STEMI). In most of them increased mortality after DES implantation was not confirmed, with demonstrated reduction of repeat revascularizations. However, long-term follow-up of these studies and the results from non-randomized "real world" registries are equivocal. A new generation of DES has been present on the market for several years. They have modern designs, are covered with more neutral polymers and release new drugs. The new generation DES have a better safety and efficacy profile, including a population of patients with acute STEMI, than the first generation stents. This paper is a review of randomized controlled trials, meta-analyses and registries, comparing DES with BMS in patients with acute STEMI. Attention was drawn to the current position and the role of new generation DES, which may prove to be a safe and effective choice in this population of patients.
\end{abstract}

Key words: acute myocardial infarction, drug-eluting stents.

\section{Introduction}

Primary percutaneous coronary intervention $(\mathrm{PPCl})$ in ST-segment elevation myocardial infarction (STEMI) is aimed at rapid opening of the infarct-related artery. It is also important to keep the vessel patency as long as possible. Primary percutaneous coronary intervention showed benefits in mortality reduction over pharmacological treatment [1] and angioplasty with bare metal stents (BMS) showed benefits in reduction of the need of repeat revascularization over balloon angioplasty [2]. Widespread introduction of drug-eluting stents (DES) for elective percutaneous interventions led to significant reduction of restenosis or the need for repeat revascularization [3]. However, the place of DES in PPCI has not been determined for many years. This was influenced by initial reports based on the general population about increased risk of in-stent thrombosis, especially late after DES implantation, which may translate into higher mortality $[4,5]$.
In-stent thrombosis may occur after DES and BMS implantation $[6,7]$. The risk factors of in-stent thrombosis include wrong stent size, prolonged endothelial healing and increased inflammatory parameters, which may occur more often in DES than BMS, as well as several factors not related to the stent itself, such as the presence of thrombus, resistance to antiplatelet drugs or their premature cessation. Many of these factors may coexist in acute myocardial infarction $[8,9]$. In order to explain these observations, a number of randomized clinical trials comparing first-generation DES with BMS in STEMI were conducted - most did not confirm increased mortality after DES implantation and reported reduction in repeat revascularizations. However, the results of long-term observations in these studies as well as results of non-randomized registries (the so-called "real world") are not so clear. Second generation DES, which have been present on the market for a few years now, may prove to be safer and more effective in the population of STEMI patients in comparison to first-generation stents.

\section{Corresponding author:}

Piotr Kübler MD, PhD, Department of Cardiology, Military Hospital, 5 Weigla St, 50-981 Wroclaw, Poland, tel.: +48 717660452 ,

e-mail: pkubler75@gmail.com

Received: 15.11.2012, accepted: 21.01.2013. 


\section{Randomized studies}

There have been several large randomized studies comparing both types of stents. In one of the first, MULTISTRATEGY, patients were randomized to receive tirofiban or abciximab and subsequently sirolimus-eluting stents (SES) or BMS [10]. The number of major adverse cardiac events after 8 months was significantly lower in the SES group (7.8\%) than in the BMS group (14.5\%), mainly due to reduction of repeat revascularizations with comparable frequency of in-stent thrombosis. Similar results were reported in the TYPHOON study, in which 712 patients were randomized to SES or BMS [11]. Combined end-point consisting of death, myocardial infarction and repeat target vessel revascularization (TVR) was $7.3 \%$ in the SES group and $14.3 \%$ in the BMS group $(p=0.004)$ after 12 months of observation, similarly due to TVR reduction. The SESAMI study showed reduction of restenosis in the SES group in comparison to the BMS group (11.1\% vs. $15.4 \% ; p=0.12)$ after 12 months with no difference in the frequency of other cardiovascular incidents in 320 patients [12].

The PASSION study compared paclitaxel-eluting stents (PES) with BMS in 619 patients with STEMI [13]. One-year observation did not demonstrate significant differences in terms of cardiac death, myocardial infarction, repeated target lesion revascularization (TLR) or in-stent thrombosis with a preserved trend towards benefit of PES use $(R R=0.63$, $p=0.09$ ). The MISSION study analyzed the frequency of stent malapposition and late lumen loss after SES and BMS implantation in 310 patients with STEMI [14]. Late lumen loss after 9 months was higher in the BMS group and stent malapposition after 12 months was more frequent in the SES group (37.5\% vs. $12.5 \% ; p<0.001)$, which however did not translate into higher frequency of cardiac incidents and led to less need for repeat revascularization (SES 2.5\% vs. BMS 7.9\%; $p=0.03$ ). Another large randomized study, DEDICATION, compared the use of DES and BMS with or without distal protection in 626 patients [15]. Late lumen loss was significantly lower after DES use and the combined end-point consisting of cardiac death, myocardial infarction and TLR occurred significantly less often in the DES group (8.9\% vs. $14.4 \% ; p=0.03$ ).

Despite some differences in the construction of the described studies, regarding also the concomitant therapy, there was no significant difference in the number of deaths, myocardial infarctions or incidents of in-stent thrombosis between studied groups with reduction of the need for repeated revascularization (TVR or TLR) after DES use in most of these studies. It should be noted that most of the cited randomized trials were based on observation periods shorter than 1 year and therefore the results of longterm observation were highly expected.

Most of them confirmed lack of increased risk of adverse cardiovascular events after DES implantation with decreased number of repeated revascularizations. However, some of the studies reported increased cardiac mortality not direct- ly related to myocardial infarction after DES implantation [16] and a trend towards increased frequency of late and very late in-stent thrombosis during 5 -year observation $[17,18]$. It should be noted that these observations regarded first-generation DES.

In spite of the above controversies, important results came from one of the largest studies including more than three and a half thousand patients and over 3 years of observation: HORIZONS-AMI (Harmonizing Outcomes with Revascularization and Stents in Acute Myocardial Infarction). This study compared the use of bivalirudin with heparin and glycoprotein Ilb/IIla inhibitor and paclitaxel-eluting stents with bare metal stents in STEMI patients. There were no differences in the number of major adverse cardiovascular events between DES and BMS groups with a significant reduction of repeated TLR in the DES group in short- and long-term observation [19]. There is a very interesting subanalysis of this study, in which a simple indicator of restenosis was used to determine groups of low, intermediate and high risk of restenosis. It was found that in patients at low risk of restenosis repeated revascularization was done with similar frequency in PES and BMS groups [20]. From a clinical standpoint it is important to mention the qualification criteria for high risk of restenosis: vessel diameter $\leq 3 \mathrm{~mm}$, lesion length $\geq 30 \mathrm{~mm}$ and insulin-dependent diabetes mellitus. Patients from this group benefited the most from DES implantation.

\section{New-generation drug-eluting stents}

A new generation of DES has been available for a few years, but its observation period is relatively short. New constructs include more compatible biological polymers (less pro-inflammatory or endothelium damaging) or biodegradable polymers, or do not have a polymer. They elute new substances such as everolimus, zotarolimus or biolimus.

Safety of new-generation DES (everolimus coated) in STEMI was confirmed in the EXAMINATION study (Evaluation of Xience V Stent in Acute Myocardial Infarction). An advantage of this study was less restrictive inclusion criteria (the so-called "all comers"), so the studied group was similar to the population of patients treated on a daily basis [21]. In comparison to cobalt-chromium stents there were no differences in combined end-point (death, myocardial infarction, any repeated revascularization) with less frequent occurrence of in-stent thrombosis and repeated TLR in patients treated with everolimus-eluting stents at 1-year observation. Even more encouraging results were observed in the COMFORTABLE-AMI study (Comparison of Biomatrix Versus Gazelle in ST-Elevation Myocardial Infarction) [22]. During 1 year from STEMI biolimus-coated stents with biodegradable polymer significantly reduced the number of cardiovascular incidents in comparison to BMS (4.3\% vs. $8.7 \%$; $p=0.004)$. There was a significant reduction of repeated TLR and myocardial infarctions from the infarct-related artery with a statistically insignificant difference in in-stent thrombosis. 
New-generation DES were compared to first-generation DES. In the XAMI study (XienceV Stent vs. Cypher Stent in Primary PCI for Acute Myocardial Infarction) everolimus-eluting stents turned out to be equally effective and safe as SES and demonstrated a powerful trend towards reduction of cardiovascular events at one-year observation (4.0\% vs. $7.7 \%$; $p=0.048$ ) [23]. In contrast, zotarolimus-eluting stents showed no advantage over SES and PES in terms of reduction of cardiovascular incidents [24], but demonstrated an insignificant trend towards reduction of in-stent thrombosis in one study [25]. A study using optical coherence tomography showed similar coverage of stent struts with endothelium for zotarolimus-eluting stents and BMS 6 months after STEMI [26]. There is an expected advantage of the new DES due to reduction of the risk of late in-stent thrombosis characteristic for first-generation stents, which however still requires confirmation in long-term observations.

\section{Meta-analyses of randomized studies}

Drug-eluting stents used in STEMI have also been assessed in large meta-analyses including several randomized clinical trials. It should be noted however that they were mostly based on observation periods up to 12 months and first-generation DES. The analysis by Pasceri et al. consisted of 7 studies (a total of 2357 patients) [27]. Major cardiovascular events occurred in $9.3 \%$ of patients in the DES group in comparison to $17.6 \%$ of patients in the BMS group $(R R=0.53,95 \% \mathrm{Cl}: 0.43-0.66)$ including more often TLR in the BMS group and similar mortality in both groups. The analysis by Dibra et al. included 14 randomized clinical trials (7781 patients) [28]. The risk of combined end-point consisting of death and myocardial infarction was similar in the DES and BMS group ( $\mathrm{HR}=0.91,95 \% \mathrm{Cl}$ : 0.75-1.09). Once again the risk of re-intervention was significantly reduced after DES implantation $(\mathrm{HR}=0.41,95 \% \mathrm{Cl}$ : 0.32-0.52). This study also showed lack of significant differences regarding survival between paclitaxel- and sirolimus-eluting stents. Another large meta-analysis, which included 13 randomized clinical trials (7244 patients), demonstrated reduction of TVR (5.11\% vs. $11.19 \% ; p=0.0001)$ and myocardial infarctions (3.03\% vs. 3.70\%; $p=0.02$ ) after DES implantation in comparison to BMS without increased frequency of in-stent thrombosis or deaths after DES [29]. At the same time SES showed an advantage over PES in terms of TVR reduction, but the analysis was limited by a short observation period (not exceeding 12 months).

The meta-analysis of Brar et al. comprised 7350 patients and a longer, 2-year, observation period. It confirmed the reduction of repeated revascularizations with the use of DES without an influence on mortality, the frequency of myocardial infarctions or in-stent thrombosis [30]. De Luca et al. analyzed 11 randomized clinical studies (6298 patients) with an even longer, over 3-year observation period [31]. There were no differences in combined deaths, myocardial infarctions and thrombosis between 2 types of stents with significant reduction of TVR in the DES group (12.7\% vs. $20.1 \%, p<0.001)$. However, the authors also drew attention to more frequent occurrence of late (over 1 year) thrombosis after DES implantation (3.1\% vs. $1.4 \%$ for BMS) and late myocardial infarctions (6.6\% for DES vs. 3.0\% for BMS). Similar conclusions were drawn by Kalesan et al. in a large meta-analysis of 15 randomized clinical trials: early benefits with the use of DES in the form of repeated revascularization and thrombosis reduction during 1 year are counterbalanced by increased risk of late thrombosis during following years of observation [32].

\section{Registries}

Results of the initial, small registries in 2004 did not show significant differences between first-generation DES and BMS in STEMI [33]. Subsequent registries demonstrated benefits from the use of DES mainly regarding the reduction of repeated revascularizations in short-term observation. However, in the RESEARCH and T-SEARCH registries (505 patients), including 3-year observation, the number of cardiovascular events was similar, with a trend towards more frequent occurrence of thrombosis in drug-eluting stents (BMS $=1.6 \%, \mathrm{SES}=2.7 \%, \mathrm{PES}=2.9 ; p=\mathrm{NS})$ [34].

A lot of confusion was caused by the results of another registry, GRACE (Global Registry of Acute Coronary Events), which were presented during the Congress of the European Society of Cardiology in 2007. Although there were no differences between DES (569 patients) and BMS use (1729 patients) within 180 days after infarction, there was an increase in mortality after DES implantation observed between 180 and 730 days following infarction [35]. Recently published results of many years of observation of a large base of 1463 patients after STEMI demonstrated higher incidence of very late (> 1 year) in-stent thrombosis and myocardial infarctions after DES implantation [36]. Implantation of drug-eluting stent was the only independent risk factor of very late in-stent thrombosis in this analysis $(H R=3.79$, 95\% Cl: 1.64-8.79; $p=0.002$ ).

Contrary to these data other large registries showed reduction of the mortality risk after implantation of drug-eluting stents in comparison to BMS. The New York State Registry demonstrated reduction of the mortality risk after DES use (1154 patients) in comparison to BMS (772 patients) $(5.0 \%$ vs. $8.6 \% ; p=0.007$ ) [37] and the Massachusetts State Registry comprising 7217 patients with STEMI confirmed reduction of mortality in patients who received DES in comparison to BMS in 2-year observation ( $8.5 \%$ vs. $11.6 \% ; p=0.008$ ) [38]. Also from our observations DES are not inferior to BMS in terms of safety and efficacy [39].

\section{Concerns}

Randomized clinical trials use predefined inclusion and exclusion criteria. This results in the fact that patients in these studies do not represent the whole spectrum of patients hospitalized on a daily basis; the most frequent 
exclusion criteria include cardiogenic shock, late presentation, rescue $\mathrm{PCl}$ after fibrinolysis and advanced age of patients. Therefore it is also important to follow the results of large registries and draw conclusions based on many sources. For some subpopulations the choice of therapy may be different than for the rest.

The are no clear data indicating whether a 12-month period of dual antiplatelet therapy after DES implantation is an optimal management for all; some groups of patients may benefit from a longer and some from a shorter period of treatment. The phenomena of aspirin and clopidogrel resistance set the stage for a new group of antiplatelet drugs, which are also studied in the setting of acute myocardial infarction. It should also be mentioned that the indication for intake of dual antiplatelet drugs for the obligatory period of time is not respected by some of the patients, which dramatically increases the risk of in-stent thrombosis after DES implantation.

\section{Conclusions}

The newest guidelines of the European Society of Cardiology on the management of patients with STEMI from 2012 recommend the use of DES in all patients without contraindications to prolonged use of dual antiplatelet therapy - class Ila [40]. Similar recommendations for DES use in STEMI (class Ila, earlier IIb) are present in the guidelines of the American cardiology societies [41]. Experts of the Polish Society of Cardiology do not preclude the use of DES, whose efficacy is proved in a selected population of STEMI patients [42].

It seems that, similarly to other difficult decisions in medicine, the choice of stent in myocardial infarction should be individualized and based on common sense. The benefits of DES use through reduction of restenosis should be evaluated against possible increased risk of very late in-stent thrombosis. Drug-eluting stents have found their place in STEMI, but not in all patients. If the lesion is complex, includes bifurcations or long artery segments, is located in small vessels or occurs in patients with diabetes, it is worth using DES. Restenosis is not a benign phenomenon and manifests with unstable angina or myocardial infarction in over one third of patients [43], and therefore it should be prevented. If there is a risk of patient's non-compliance, the patient is to undergo planned surgery during 12 months or the risk of bleeding complications is rated as increased, it is better to use BMS. The problem is that decisions in acute myocardial infarction have to be fast and data from the patient's medical history are often incomplete.

In conclusion, there is an increasing amount of data on the advantages of new-generation DES, having a larger margin of safety and efficacy. They reduce the need of repeated revascularizations with only a slightly increased risk of late and very late in-stent thrombosis. It seems that the battle will be resolved very quickly in their favor, but ultimately it has to be confirmed in further studies with longer follow-up.

\section{References}

1. Keeley EC, Boura JA, Grines CL Primary angioplasty versus intravenous thrombolytic therapy for acute myocardial infarction: a quantitative review of 23 randomised trials. Lancet 2003; 361: 13-20.

2. De Luca G, Suryapranata H, Stone GW, et al. Coronary stenting versus balloon angioplasty for acute myocardial infarction: a meta-regression analysis of randomized trials. Int J Cardiol 2008; 126: 37-44.

3. Kastrati A, Mehilli J, Pache J, et al. Analysis of 14 trials comparing sirolimus-eluting stents with bare-metal stents. N Engl J Med 2007; 356: 1030-1039.

4. Pfisterer M, Brunner-La Rocca HP, Buser PT, et al. Late clinical events after clopidogrel discontinuation may limit the benefit of drug-eluting stents: an observational study of drug-eluting versus bare-metal stents. J Am Coll Cardiol 2006; 48: 2584-2591.

5. Lagerqvist B, James SK, Stenestrand U, et al. Long-term outcomes with drug-eluting stents versus bare-metal stents in Sweden. N Engl J Med 2007; 356: 1009-1019.

6. Tolleson TR, Newby LK, Harrington RA, et al. Frequency of stent thrombosis after acute coronary syndromes (from the SYMPHONY and 2nd SYMPHONY trials). Am J Cardiol 2003; 92: 330-333.

7. Daemen J, Wenaweser P, Tsuchida K, et al. Early and late coronary stent thrombosis of sirolimus-eluting and paclitaksel-eluting stents in routine clinical practice: data from a large two-institutional cohort study. Lancet 2007; 369: 667-678.

8. Hong MK, Mintz GS, Lee CW, et al. Late stent malapposition after drug-eluting stent implantation: an intravascular ultrasound analysis with long-term follow-up. Circulation 2006; 113: 414-419.

9. Luscher TF, Steffel J, Eberli FR, et al. Drug-eluting stent and coronary thrombosis: biological mechanisms and clinical implications. Circulation 2007; 115: 1051-1058.

10. Valgimigli M, Campo G, Percoco G, et al. Comparison of angioplasty with infusion of tirofiban or abciximab and with implantation of sirolimus-eluting or uncoated stents for acute myocardial infarction: the MULTISTRATEGY randomized trial. JAMA 2008; 299: 1788-1799.

11. Spaulding C, Henry P, Teiger E, et al. Sirolimus-eluting versus uncoated stents in acute myocardial infarction. N Engl J Med 2006; 355: 1093-1104.

12. Menichelli M, Parma A, Pucci E, et al. Randomized trial of SirolimusEluting Stent Versus Bare-Metal Stent in Acute Myocardial Infarction (SESAMI). J Am Coll Cardiol 2007; 49: 1924-1930.

13. Laarman GJ, Suttorp MJ, Dirksen MT, et al. Paclitaxel-eluting versus uncoated stents in primary percutaneous coronary intervention. N Engl J Med 2006; 355: 1105-1113.

14. Van der Hoeven BL, Liem SS, Jukema JW, et al. Sirolimus-eluting stents versus bare-metal stents in patients with ST-segment elevation myocardial infarction: 9-month angiographic and intravascular ultrasound results and 12-month clinical outcome results from the MISSION! Intervention Study. J Am Coll Cardiol 2008; 51: 618-626.

15. Kelbaek H, Thuesen L, Helquist S, et al. Drug-eluting versus bare metal stents in patients with ST-segment-elevation myocardial infarction: eight-month follow-up in the Drug Elution and Distal Protection in Acute Nyocardial Infarction (DEDICATION) trial. Circulation 2008; 118: 1155-1162.

16. Kaltoft A, Kelbaek H, Thuesen L, et al. Long-term outcome after drugeluting versus bare-metal stent implantation in patients with STelevation myocardial infarction: 3-year follow-up of the randomized DEDICATION trial. J Am Coll Cardiol 2010; 56: 641-645.

17. Boden H, van der Hoeven BL, Liem SS, et al. Five-year clinical follow-up from the MISSION! Intervention Study: sirolimus-eluting stent versus bare metal stent implantation in patients with ST-segment 
elevation myocardial infarction, a randomised controlled trial. Eurointervention 2011; 7: 1021-1029.

18. Vink MA, Dirksen MT, Suttorp MJ, et al. 5-Year follow-up after primary percutaneous coronary intervention with a paclitaxel-eluting stent versus a bare-metal stent in acute ST-segment elevation myocardial infarction. J Am Coll Cardiol Int 2011; 4: 24-29.

19. Stone GW, Lansky AJ, Pocock SJ, et al. Paclitaxel-eluting stents versus bare-metal stents in acute myocardial infarction. N Engl J Med 2009; 360: 1946-1959.

20. Stone GW, Parise H, Witzenbichler B, et al. Selection criteria for drug eluting versus bare-metal stents and the impact of routine angiographic follow-up 2-year insights from the HORIZONS-AMI (Harmonizing Outcomes with Revascularization and Stents in Acute Myocardial Infarction) trial. J Am Coll Cardiol 2010; 56: 1597-1604.

21. Sabate M, Cequier A, Iniguez A, et al. Rationale and design of the EXAMINATION trial: a randomised comparison between everolimuseluting stents and cobalt-chromium bare-metal stents in ST-elevation myocardial infarction. Eurointervention 2011; 7: 977-984.

22. Raber L, Kelbaek H, Ostoijc M, et al. Effect of biolimus-eluting stents with biodegradable polymer vs bare-metal stents on cardiovascular events among patients with acute myocardial infarction. The COMFORTABLE AMI randomized trial. JAMA 2012; 308: 777-787.

23. Hofma SH, Brouwer J, Velders MA, et al. Second-generation everolimus-eluting stents versus first-generation sirolimus-eluting stents in acute myocardial infarction. J Am Coll Cardiol 2012; 60: 381-387.

24. Kang WC, Ahn T, Lee K, et al. Comparison of zotarolimus-eluting stents versus sirolimus-eluting stents versus paclitaxel-eluting stents for primary percutaneous coronary intervention in patients with ST-elevation myocardial infarction: results from the Korean Multicentre Endeavor (KOMER) acute myocardial infarction (AMI) trial. Eurolntervention 2011; 7: 936-943.

25. Lee CW, Park DW, Lee SH, et al. Comparison of the efficacy and safety of zotarolimus-, sirolimus-, and paclitaxel-eluting stents in patients with ST-elevation myocardial infarction. Am J Cardiol 2009; 104: 1370-1376.

26. Guagliumi G, Sirbu V, Bezerra H, et al. Strut coverage and vessel wall response to zotarolimus-eluting and bare-metal stents implanted in patients with ST-segment elevation myocardial infarction: the OCTAMI (Optical Coherence Tomography in Acute Myocardial Infarction) Study. JACC Cardiovasc Interv 2010; 3: 680-687.

27. Pasceri V, Patti G, Speciale G, et al. Meta-analysis of clinical trials on use of drug-eluting stents for treatment of acute myocardial infarction. Am Heart J 2007; 153: 749-754.

28. Dibra A, Tiroch K, Schulz S, et al. Drug-eluting stents in acute myocardial infarction: updated meta-analysis of randomized trials. Clin Res Cardiol 2010; 99: 345-357.

29. Piscione F, Piccolo R, Cassese S, et al. Effect of drug-eluting stents in patients with acute ST-segment elevation myocardial infarction undergoing percutaneous coronary intervention: a meta-analysis of randomized trials and an adjusted indirect comparison. Eurointervention 2010; 5: 853-860.
30. Brar S, Leon M, Stone G et al. Use of drug-eluting stents in acute myocardial infarction. A systematic review and meta-analysis. J Am Coll Cardiol 2009; 53: 1677-1689.

31. De Luca G, Dirksen MT, Spaulding C, et al. Drug-eluting versus baremetal stents in primary angioplasty. A pooled patient-level metaanalysis of randomized trials. Arch Intern Med 2012; 172: 611-621.

32. Kalesan B, Pilgrim T, Heinimann K, et al. Comparison of drug-eluting stents with bare metal stents in patients with ST-segment elevation myocardial infarction. Eur Heart J 2012; 33: 977-987.

33. Lemos PA, Saia F, Hofman SH, et al. Short- and long-term clinical benefit of sirolimus-eluting stents compared to conventional bare stents for patients with acute myocardial infarction. J Am Coll Cardiol 2004; 43: 704-708.

34. Daemen J, Tanimoto S, Garcia-Garcia HM, et al. Comparison of threeyear clinical outcome of sirolimus- and paclitaxel-eluting stents versus bare metal stents in patients with ST-segment elevation myocardial infarction (from the RESEARCH and T-SEARCH Registries). Am J Cardiol 2007; 99: 1027-1032.

35. Steg PG, Fox KA, Eagle KA, et al. Mortality following placement of drug-eluting and bare-metal stents for ST-segment elevation acute myocardial infarction in the Global Registry of Acute Coronary Events. Eur Heart J 2009; 30: 321-329.

36. Brodie B, Pokharel Y, Fleishman N, et al. Very late stent thrombosis after primary percutaneous coronary intervention with baremetal and drug-eluting stents for ST-segment elevation myocardial infarction: a 15-year single-center experience. J Am Coll Cardiol Int 2011; 4: 30-38.

37. Hannan EL, Racz M, Walford G, et al. Drug-eluting versus bare metal stents in the treatment of patients with ST-segment elevation myocardial infarction. J Am Coll Cardiol Int 2008; 1: 129-135.

38. Mauri L, Silbaugh TS, Garg P, et al. Drug-eluting or bare-metal stents for acute myocardial infarction. N Engl J Med 2008; 359: 1330-1342.

39. Kübler $P$, Jankowska EA, Ferenc $M$, et al. Comparison of drug-eluting stents to bare-metal stents in ST-elevation myocardial infarction in long-term follow-up. Kardiol Pol 2013; 71: 25-31.

40. Steg G, James SK, Atar D, et al. ESC Guidelines for the management of acute myocardial infarction in patients presenting with ST-segment elevation. Eur Heart J 2012; 33: 2569-2619.

41. Kushner FG, Hand M, Smith SC, et al. 2009 focused updates: ACC/AHA guidelines for the management of patients with ST-elevation myocardial infarction (updating the 2004 guideline and 2007 focused update) and ACC/AHA/SCAI guidelines on percutaneous coronary intervention (updating the 2005 guideline and 2007 focused update) a report of the American College of Cardiology Foundation/American Heart Association Task Force on Practice Guidelines. J Am Coll Cardiol 2009; 54: 2205-2241.

42. Witkowski A, Opolski M, Dudek D, et al. Current status of drug-eluting stents and drug-eluting balloons in patients with stable coronary artery disease: an expert consensus document of the Association for Percutaneous Cardiovascular Interventions and the Polish Cardiac Society. Postep Kardiol Inter 2011; 7: 20-55.

43. Chen MS, John JM, Chew DP, et al. Bare metal stent restenosis is not a benign clinical entity. Am Heart J 2006; 151: 1260-1264. 